\title{
Wartime migration and the incidence of tuberculosis in the Zagreb region, Croatia
}

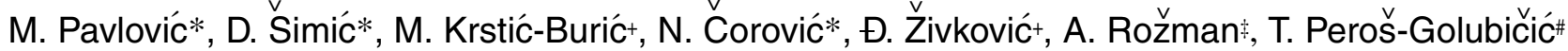

Wartime migration and the incident of tuberculosis in the Zagreb region, Croatia. M. Pavlović, D. Šimić, M. Krstić-Burić, N. Corović, Đ. Živković A. Rožman, T. Peroš-Golubičić. (C) ERS Journals Ltd 1998.

ABSTRACT: The objective of the present study was to investigate the rate of decline in the incidence of tuberculosis (TB) in residents (1985-1994) and in refugees and displaced persons (1992-1994) during prewar and war periods (1985-1994) in the region of Zagreb, Croatia, and to examine a possible change in the trend of decline in the resident population.

Data on the incidence of TB were obtained from the Epidemiology Department, Institute for Lung Diseases, Zagreb, Croatia. The sample comprised two groups of subjects: residents $(800,000-1,000,000$ inhabitants) and all refugees and displaced persons temporarily residing in the Zagreb region (78,000-95,000 persons). Data were analysed by stepwise logistic regression.

The most significant predictors of the TB incidence rate were the square of the year and residence status. The rate of $\mathrm{TB}$ incidence in nonresidents was significantly higher than in residents. The decline in incidence in residents was significantly slower than in the nonresident group.

The results did not indicate a potential change in the natural decline of the incidence of tuberculosis in the resident population during the study periods. The difference between the regression trends of the incidence of tuberculosis in residents and nonresidents was the result of various concomitant factors, including artefacts of the war. Eur Respir J 1998; 12: 1380-1383.

One of the consequences of the war (1991-1995) in the former Yugoslavia was migration. Migration was most intensive in Croatia at the beginning of the war (19911992) and in 1995. In Bosnia and Herzegovina war, and migration occurred later (1992-1993, 1995). Croatia accepted a large number of displaced persons and refugees. They came primarily from the Pannonian region of Croatia and from Bosnia and Herzegovina. A smaller number of nonresidents originated from SR Yugoslavia (Voivodina, Kosovo and Montenegro). Approximately $50 \%$ of the nonresidents were cared for in the region of Zagreb, the capital of Croatia. The Zagreb region is a densely populated area with a population of one million inhabitants (approximately $25 \%$ of the total Croatian population), comprising 13 urban and 12 periurban communities. Owing to war migration the population increased by approximately $10 \%$.

Displaced persons and refugees have been cared for by the National Health Service, with the interest and help of international humanitarian organizations $[1,2]$. Particular attention has been paid to tuberculosis (TB) $[3,4]$. In the former Yugoslavia the incidence rates of TB of all systems were among the highest in Europe [5]. Acceptance of a large number of refugees originating from former Yugoslavia is a reason for epidemiological concern in the states of former Yugoslavia, as well as in neighbouring European countries [6-8].

In the prewar and wartime periods the average annual incidence rate of TB in the Zagreb region was above the
*Institute for Medical Research and Occupational Health, Zagreb, Croatia. ${ }^{+}$Fund for Disability and Retirement Insurance of Croatia, Zagreb, Croatia. \$Dept of Preventive Medicine Institute for Tuberculosis and Pulmonary Disease, Zagreb, Croatia \#Jordanovac University Hospital for Lung Diseases, Zagreb, Croatia

Correspondence: M. Pavlović

Institute for Medical Research and Occupational Health

Ksaverska c. 2, P.O. Box 291

HR-10001 Zagreb

Croatia

Fax: 38514673303

Keywords: Incidence of tuberculosis, war migrations

Received: April 21997

Accepted after revision April 181998

Supported by the Croatian Ministry of Science and Technology (TID 00220307) average for Croatia and showed a steady decline. Within and between urban and periurban communities the incidence rates of TB in the resident population were not uniform. For example, in 1992, communities where the incidence of TB was $40-80$ per 100,000 accounted for $71.6 \%$ of the population, while those where the incidence of TB was $<40$ per 100,000 accounted for $16.9 \%$ and those with an incidence $>80$ per 100,000 accounted for $11.5 \%$ of the total resident population [9]. Furthermore, the incidence rates were diverse in areas from which the displaced persons and refugees originated. For example, in 1988, the incidence in Bosnia and Herzegovina was 87.3 per 100,000 inhabitants and in Croatia it was 63.2 per 100,000 inhabitants [10]. The Pannonian region, from which most of the displaced persons originated, is a region of Croatia with a very high incidence of TB. For example, in 1996, incidence rates ranged $100-150$ per 100,000 inhabitants [11].

Reports from the former Yugoslavia reveal a disturbance in the epidemiological indicators of tuberculosis infections [12-14].

The aim of this study was to elucidate a possible interaction between the incidence rates of all forms of TB in residents and nonresidents, and the impact of wartime migration on the incidence of TB in the resident population in the Zagreb area. A model is proposed for the evaluation of the implications of wartime migration on the occurrence of the disease in resident populations in densely populated regions. 


\section{Subjects and methods}

Urban and periurban health clinics ( $\mathrm{n}=25)$, hospitals for lung diseases and TB and pulmonary departments of general hospitals $(n=6)$ are obliged to register all patients with TB by sending a standardized form to the Epidemiological Service Department of Preventive Medicine of the Institute for Lung Diseases, Zagreb [9, 11, 15].

The sample consisted of inhabitants in the Zagreb region during 1985-1994. It included two groups: residents, and displaced persons and refugees (nonresidents). Patients with newly registered and/or relapsing TB of all systems were recorded. The diagnostic methods used were microbiology and serial radiography and/or radiographic examination. Patients who started and responded to initial treatment were reported as cases. All displaced persons and refugees were granted standard medical insurance by the Croatian Fund for Health and Health Care. Procedures for detecting and registering TB did not differ for residents and displaced persons and refugees. From 1985 to 1992 the proportion of microbiologically confirmed cases in Croatia increased from 56 to $64 \%$. There was no difference in the proportion of microbiologically confirmed cases between the analysed groups [9]. Medical histories of nonresidents were taken in an interview. Because of the forbidding number of displaced persons and refugees it was impossible to organize medical screening at the time of arrival. Official records were unavailable (mostly destroyed) and thus estimates of the incidence rates for nonresidents relied on their statement that they had not previously had TB. The number of residents in individual years (1985-1995) was estimated on the basis of the 1981 and 1991 population censuses [16, 17]. The number of nonresidents was taken from annual reports (1992-1994) [18].

Annual incidence rates of TB were modelled using stepwise logistic regression with the entry significance level set at 0.05 and the staying significance level set at 0.10 . The analysis was performed on a personal computer using SAS 6.12 PROC LOGISTIC (SAS Institute, Cary, NC, USA) [19]. Predictors were $\mathrm{yr}$ and $\mathrm{yr}^{2}$ (to account for a possible nonlinear trend), group indicator (1: nonresidents; 0 : residents), group $\times y r$ interaction (0: residents, 1 : refugees in 1993; 2 refugees in 1994) and migration $\times y r$ interaction (0: refugees; 1 : residents in 1993; 2 : residents in 1994). The model enabled the testing of several hypotheses. Regression coefficients for $\mathrm{yr}$ and $\mathrm{yr}^{2}$ described the overall trend of the incidence rate of TB. The coefficient for the group was an estimate of the average difference between the incidence rates of TB for nonresidents and residents in corresponding yrs. The coefficient for the group $\times y r$ interaction estimated the difference in the linear trend between the incidence rates of TB for nonresidents and that for residents. Similarly, the coefficient for migration $\times y r$ interaction assessed the change in the trend of the incidence rate of TB for residents. Candidate models were also compared regarding the Akaike information criterion (AIC), $-2 \log$ likelihood (-2 log L) and the Schwartz criterion (SC). The influential observations were determined using $\operatorname{df} \beta$ and the change in deviation due to deletion of the observation. The df $\beta$ diagnostics measure the effects of individual observations on parameter estimates. They are computed as a standardized difference in the parameter estimate due to deleting the corresponding observation.
Goodness of fit was assessed using deviance statistics. Standard errors of estimated parameters were inflated to account for overdispersion [20].

\section{Results}

Table 1 presents the number of cases in the sample. In 1994 some periurban communities ceased to be under the city jurisdiction. Within both groups of communities, i.e. those under Zagreb jurisdiction and those excluded, incidences varied. However, the overall incidence in the excluded communities did not essentially differ from the incidence in communities which stayed within the Zagreb jurisdiction. The majority of nonresidents (approximately $60 \%$ ) in the Zagreb region lived in refugee centres located within Zagreb jurisdiction. The excluded communities accounted for an insignificant number of nonresidents (approximately 5\%). At the end of 1993 and during 1994 a number of nonresidents were transferred from Zagreb to other refugee centres. The resident population differed from the nonresidents with regard to age and sex. For instance, in $1993,32 \%$ of the residents and $37 \%$ of the nonresidents were $<24 \mathrm{yrs}$ old and $52.7 \%$ of the residents and $62.0 \%$ of the nonresidents were females [16]. Generally, there were fewer middle-aged males in the group of nonresidents. Age and sex breakdown for nonresidents was not available for all of the analysed years. Although age and sex breakdown for residents could be estimated from the 1981 and 1991 censuses, intercensal estimates for subgroups are, in general, less accurate than those for the entire population. Furthermore, age and sex breakdown for nonresidents would create some very small groups and possibly invalidate the proposed methodology.

According to the incomplete data, the average incidence rate of TB for Bosnia and Herzegovina in 1994 was 53 per 100,000 (higher than for the Zagreb region) [21]. Unfortunately, owing to the war, data for 1992 and 1993 are unavailable. Their variability (e.g. Sarajevo 100 per 100,000 [21]) may have also influenced the incidence rate of TB for nonresidents. In March 1992, refugees from Bosnia and Herzegovina constituted approximately $39 \%$ of the nonresident population and displaced persons from the Pannonian region of Croatia approximately 30\% [18]. During the war the composition and the number of nonresidents fluctuated. Thus, in 1993, almost half of all the nonresidents were from east Slavonia, part of the Pannonian region

Table 1. - Number of new cases of tuberculosis and total number of residents, displaced persons and refugees in the Zagreb region

\begin{tabular}{lcclcr}
\hline & \multicolumn{2}{c}{ Residents } & & \multicolumn{2}{c}{ Nonresidents } \\
\cline { 2 - 3 } Year & Cases & Total & & Cases & Total \\
\hline 1985 & 907 & 1216825 & & & \\
1986 & 959 & 1229034 & & & \\
1987 & 977 & 1206172 & & & \\
1988 & 807 & 1200936 & & & \\
1989 & 821 & 1192928 & & & \\
1990 & 741 & 1160725 & & & \\
1991 & 601 & 1180075 & & 91 & 94539 \\
1992 & 656 & 1224602 & & 81 & 119428 \\
1993 & 658 & 1249297 & & 39 & 78876 \\
1994 & 386 & 933946 & & &
\end{tabular}


[18]. However, some nonresidents (approximately 5\%) originated from areas with a lower incidence rate of TB than the Zagreb region (e.g. incidence rate of TB in the ZadarKnin region 18 per 100,000) [11]. A crude estimate, based on these values, would place the average domicile incidence for nonresidents in March 1992 at 74 per 100,000, i.e. below the recorded 1992 value.

Table 2 shows the results of the logistic regression. The stepwise procedure retained $\mathrm{yr}^{2}$ group and group $\times \mathrm{yr}$ interaction. The remaining predictors did not improve the model fit. The $\chi^{2}$-tests for score and $-2 \log \mathrm{L}$ showed that the included predictors were highly significant $(\mathrm{p}<0.0001$ and $\mathrm{p}<0.00001$ ). Among the candidate models, the chosen model had the smallest value of AIC and $-2 \log$ L. According to SC the group $\times y r$ interaction could also be excluded. The AIC, SC and $-2 \log \mathrm{L}$ values were relatively large and showed that additional predictors were necessary to improve the model fit. The deviance goodness-of-fit statistic was 29.99, with 9 degrees of freedom, implying overdispersion or the need for additional predictors. Overdispersion was to be expected, owing to the variability in incidences within the analysed populations and other unaccounted sources of variability (e.g. sex, age, socioeconomic status, etc.).

The most significant predictor of the incidence of TB was $\mathrm{yr}^{2}$, with the negative regression coefficient. This result corroborated the known trend. The inclusion of group in the model implied that the difference in the average incidence rates of TB for nonresidents and residents in 1992-1994 was significant. The significance of the group $\times y r$ interaction with a negative coefficient indicated that the decline in the incidence rate of TB in nonresidents was greater than in the resident population. After correction for overdispersion, the group $\times y r$ interaction parameter was not significant at the $p=0.05$ level. However, the estimated odds ratio for a one-yr decline in TB incidence in refugees and displaced persons corresponded to the crude odds ratio estimated from raw data in table 1 .

The observed and predicted incidences of TB with $95 \%$ confidence intervals for prediction are shown in table 3 and graphically in figure 1 .

The largest values of df $\beta$ were 1.6 for regression coefficient for $\mathrm{yr}^{2}$ in 1994 for residents and 1.4 for the intercept in 1987 . Other values of $\operatorname{df} \beta$ were $<1$. For regression coefficients with group and group $\times \mathrm{yr}, \mathrm{df} \beta$ for all observations were $<0.41$. The change in deviance due to deleting an individual observation was high for 1987, 1991 and 1993 in the resident population. All of the observations were retained in the analysis.
Table 3. - Observed and predicted incidence of active tuberculosis in the Zagreb region

\begin{tabular}{lcclll}
\hline Year & \multicolumn{2}{c}{ Incidence per 100,000 } & & \multicolumn{2}{c}{ 95\% Confidence limits } \\
\cline { 2 - 3 } \cline { 5 - 6 } & Observed & Predicted & & Lower & Upper \\
\hline Residents & & & & & \\
1985 & 74.5 & 77.9 & & 73.4 & 82.6 \\
1986 & 78.0 & 76.5 & & 72.3 & 80.9 \\
1987 & 81.0 & 74.2 & & 70.4 & 78.2 \\
1988 & 67.2 & 71.1 & & 67.9 & 74.5 \\
1989 & 68.8 & 67.4 & & 64.6 & 70.3 \\
1990 & 63.8 & 63.1 & & 60.5 & 65.7 \\
1991 & 50.9 & 58.3 & & 55.6 & 61.2 \\
1992 & 53.6 & 53.3 & & 50.1 & 56.6 \\
1993 & 52.7 & 48.1 & & 44.3 & 52.1 \\
1994 & 41.3 & 42.9 & & 38.6 & 47.6 \\
Displaced persons and refugees & & & \\
1992 & 96.3 & 95.7 & & 67.4 & 135.9 \\
1993 & 67.8 & 68.7 & & 53.0 & 89.1 \\
1994 & 49.4 & 48.8 & & 30.1 & 78.9 \\
\hline
\end{tabular}

\section{Discussion}

Although the incidence rate of TB in the nonresident group was significantly higher than in the group of residents, it exhibited a faster decline. After accounting for overdispersion, however, the change in the rate of decline was not significant at the $p=0.05$ level. There was no significant change in the rate of decline of incidence in the resident population.

The sharp decline in the incidence rate of TB among nonresidents is difficult to explain. Incidences for nonresidents in 1992 and 1993 could be a result of higher susceptibility induced by war stress and social deprivation $[22,23]$. The decrease in incidence could be attributed to adaptation, improved healthcare and quality of life. However, while collecting data for the group of nonresidents specific omissions may have occurred. Some patients in the nonresident group, registered as TB patients in their domiciles, may have been registered again in the Zagreb region as new cases. Thus, prevalence may have been mixed with incidence. The fraction of such omissions would be proportional to that of new nonresidents, which decreases with time. This may partially account for the observed difference in the declining trend of the incidence rate of TB between the two groups.

The incidence rates in the resident population in 1987 , 1991 and 1993 were detected as influential for the fit of the model. The observed incidence was higher than predicted

Table 2. - Maximum likelihood estimates of logistic regression parameters

\begin{tabular}{|c|c|c|c|c|c|c|c|}
\hline Variable & $\begin{array}{c}\text { Parameter } \\
\text { estimate }\end{array}$ & $\begin{array}{l}\text { Standard } \\
\text { error }\end{array}$ & $\begin{array}{l}\text { Standardized } \\
\text { parameter }\end{array}$ & $\begin{array}{l}\text { Odds } \\
\text { ratio }\end{array}$ & $\chi^{2}$ & & Model fit \\
\hline Intercept & -7.1511 & 0.0308 & & & $53788.2 * * *$ & & \\
\hline $\mathrm{Yr}^{2}$ & -0.0060 & 0.0007 & -0.1063 & 0.994 & $71.5^{* * *}$ & & \\
\hline Group & 0.5864 & 0.1819 & 0.0497 & 1.798 & $10.4 * *$ & & \\
\hline Group $\times y r$ & -0.2287 & 0.1700 & -0.0237 & 0.796 & 1.8 & & \\
\hline Model fit & & & & & & & \\
\hline AIC & & & & & & 129074.14 & \\
\hline $\mathrm{SC}$ & & & & & & 129088.45 & \\
\hline$-2 \log \mathrm{L}$ & & & & & & 129072.14 & $\chi^{2}=266.7(\mathrm{df}=3, \mathrm{p}=0.0001)$ \\
\hline Score & & & & & & & $\chi^{2}=257.7(\mathrm{df}=3, \mathrm{p}=0.0001)$ \\
\hline Residual & & & & & & & $\chi^{2}=1.6(\mathrm{df}=2, \mathrm{p}=0.4560)$ \\
\hline
\end{tabular}

AIC: Akaike information criterion; SC: Schwartz criterion; L: likelihood; **: $\mathrm{p}<0.01, * * *$ : $\mathrm{p}<0.001$. 


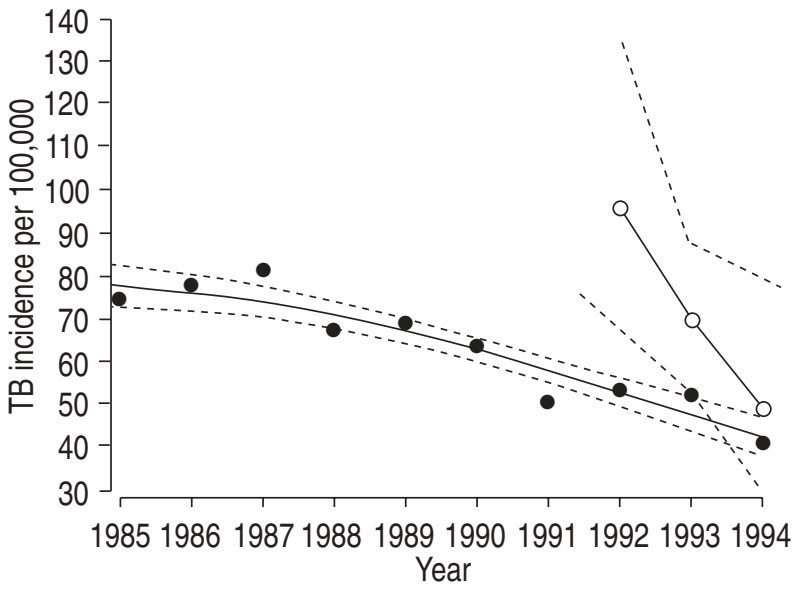

Fig. 1. - Regression line of the incidence of active tuberculosis (TB) in the Zagreb region (all forms) per 100,000 population ( $\bullet$ : residents; $\mathrm{O}$ : nonresidents) with the $95 \%$ confidence limits ( - - - ).

in 1987 and 1993, and lower in 1991. In 1986 mass radiography was abandoned in the former Yugoslavia. Whether or not this caused a delay in the reporting of TB is difficult to judge. At the beginning of the war (1991) inhabitants of the Zagreb region were frequently forced to take cover in shelters and, consequently, visits to pulmonary outpatient departments declined. The observed incidences for the resident population seem to indicate a periodicity of 3 yrs (fig. 1). Outlying observations were consistent with the observed periodicity. However, the character of the data does not support estimation of additional parameters.

Although the incidence of tuberculosis in the migrating population was significantly higher than in the resident population, the present analysis did not detect any change in the trend of incidence in residents. Investigations of the effect of World War II on the incidence rate of tuberculosis in the former Yugoslavia also indicated that the war did not have a significant effect on the natural trend of decline $[24,25]$. However, recent research in other war zones suggests that analyses should be carried out in peacetime (approximately $5 \mathrm{yrs}$ after the end of the war) to enable firm conclusions to be made [26, 27]. Unfortunately, data for Zagreb in subsequent years are not comparable owing to changes in the Health Insurance service, and it may not be possible to analyse the more recent yrs.

Acknowledgements: The authors thank $H$. Harambašić and I. Margan for their helpful suggestions, J. Cicin-Š Zagreb, for their help and co-operation.

\section{References}

1. Pavlović M, Zavalić M, Črović N, et al. Loss of body mass in ex-prisoners of war. Eur J Clin Nutrition 1993; 47: 808-814.

2. Acheson D. Health, humanitarian relief and survival in former Yugoslavia. BMJ 1993; 307: 44-48.

3. Raviglione MC, Rieder HL, Styblo K, et al. Tuberculosis trends in Eastern Europe and the former USSR. Tubercle Lung Dis 1994; 75: 400-416.

4. Felten MK, Forte GB. Prepacked kits for diagnosis and treatment of tuberculosis in former Yugoslavia. Tubercle Lung Dis 1995; 76: 360-369.
5. Radošević Z, Krstić-Burić M. Tuberculosis in Croatia. Medicus 1994; 1: 37-61 (in Croatian).

6. Enarson DA, Wang JS, Grzybowski S. Case-finding in the elimination phase of tuberculosis: tuberculosis in displaced people. Bull IUATLD 1990; 65: 71-74.

7. Eriki P. Antituberculosis measures for displaced persons. Bull IUATLD 1988; 63: 31-33.

8. Rieder HL. Epidemiology of tuberculosis in Europe. Eur Respir J 1995; 8: Suppl 20, 620s-632s.

9. Bležinkov-Zivković Đ, Zivković G. Tuberculosis and chronic pulmonary diseases in the Zagreb area 1992. Zagreb, Institute of Tuberculosis and Pulmonary Diseases, 1993.

10. Poček B, ed. Analysis of Population Health, Organisation and Activities of the Health Providers in SFRJ, 1979_ 1988. Beograd, Savezni zavod za zdravstveňu zastitu, 1990 (in Serbian).

11. Margan Gjenero I. Tuberculosis: the epidemiological situation. Lijec Vijesn 1996; 118: 301-303 (in Croatian).

12. Bogdanović N, Milenković A, Mrcić-Martinović G. TB among refugees from former SFRJ treated in 1993 at the Institute for Lung Diseases and TB, Belgrade. Tubercle Lung Dis 1995; 76: Suppl 2, 125-126.

13. Čirić Ž, Živković D, Stanković I, Pejčcić T. Epidemiological characteristics of tuberculosis in the area of increasing migration of people: the analysis of our material. Tubercle Lung Dis 1995; 76: Suppl 2, 124.

14. Mijatović M, Pavlović S. The problem of tuberculosis in Yugoslavia. Tubercle Lung Dis 1994; 75: Suppl 1, 44.

15. Ljubicicic M, Kuzman M. Report on conditions and work in the health service of the Republic of Croatia in 1990. Public Health Institute of the Republic of Croatia, Medicinska naklada, Zagreb, 1991 (in Croatian).

16. Gelo J. In: Crkvenčić Bojić J, ed. Statistical Information 1992. Zagreb, Central Bureau of Statistics of the Republic of Croatia, 1993.

17. Dakić S. Statistical Yearbook of Zagreb 1994. Zagreb, Orbis dd (in Croatian).

18. Government of the Republic of Croatia. Facts regarding the number of displaced persons and refugees (Table 1). Zagreb, Office for Displaced Persons and Refugees, 1992, 1993, 1994.

19. SAS Institute Inc. Logistic Regression Examples using the SAS System, Version 6, 1st Edn. Cary, NC, SAS Institute, 1995.

20. Hosmer DW, Lemeshow S. Applied Logistic Regression. New York, John Wiley \& Sons, 1989.

21. Luthan JM. Annual report 1994, WHO mission in former Yugoslavia, Tuberculosis Office for Europe, Zagreb Area Office. Zagreb, IGP Štefanović, 1995; pp. 30-31.

22. Davies PDO. Tuberculosis and migration. The Mitchell Lecture 1994. J R Coll Phys Lond 1995; 29: 113-118.

23. Rieder HL, Zellweger J-P, Raviglione MC, Keizer ST, Migliori GB. Tuberculosis control in Europe and international migration. Eur Respir J 1994; 7: 1545-1553.

24. Stanojević D. Rate of the relapse of pulmonary TB for the period of 10 years. Pluc Bol Tuberk 1977; 29: 13-16 (in Serbian).

25. Styblo K, Sutherland J. Epidemiological indices for planning surveillance and evaluation of tuberculosis programmes. Bull IUATLD 1974; 49: 66-73.

26. Tala E, Kochi A. Elimination of tuberculosis from Europe and the world. Eur Respir J 1991; 4: 1159-1160.

27. Sukrakanchana-Trikham P, Puechal X, Rigal J, Reider HL. 10-year assessment of treatment outcome among Cambodian refugees with sputum smear-positive tuberculosis in Khao-I-Dang, Thailand. Tubercle Lung Dis 1992; 73: 384-387. 